\title{
Integrating architectural, social and housing history
}

\author{
RODERICK J. LAWRENCE
}

The growth of interest in urban and housing history during recent decades has produced a large volume of studies that has examined broad societal parameters, or themes, such as housing policies, economics and legislation. Concurrently, a growing volume of historical research about households and families has been published, but few studies examine the lifestyles and values of the residents. In sum, there rarely has been any systematic analysis of how longitudinal developments in domestic life are related to developments in the spatial layout, the meaning and use of shared and private spaces and the daily activities these accommodate. In general, the inter-relations between the architectural, cultural and societal dimensions of housing history have commonly been overlooked. This paper argues why, and then illustrates how, integrative concepts and methods can be applied to diversify and enrich recurrent interpretations by referring to a published study of urban housing and daily life in the French-speaking cantons of Switzerland between 1860 and $1960{ }^{1}$

\section{Introduction}

Housing history has commonly examined exceptional rather than typical kinds of dwelling units. However, during the last three decades the growth of interest in urban and housing history has produced a large volume of research about building structures not often included in this field. According to Daunton, issues or themes such as public health and sanitation, housing policies, economics and building legislation, have been employed to provide the framework for many recent studies. ${ }^{2}$ There have also been studies of dwelling units built for different socio-economic classes in

1 R.J. Lawrence, Le Seuil franchi . . logement populaire et vie quotidienne en Suisse romande, 1860-1960 (Geneva, 1986).

2 M.J. Daunton, 'Experts and the environment: approaches to planning history', Journal of Urban History, 9 (1983), 333-50. 
diverse locations and societies, some limited to specific towns and others to specific periods.

Despite the growing volume of studies about the history of the family, many studies that examine housing give scant consideration to the values and lifestyles of the residents. Although there has rarely been any systematic consideration of how household life is related to the spatial organization and the furnishing of rooms, it is pertinent to examine those ideas and values related to the design and use of domestic space if we are to develop a more comprehensive understanding of housing history. This kind of approach has been published by Le Roy Ladurie in his analysis of the Inquisition Register of the Bishops of Pamiers. ${ }^{3}$ Whereas the majority of current knowledge of vernacular housing and domestic life during the Middle Ages has come from archaeological fieldwork, or from painting of that epoch, Le Roy Ladurie's analysis of this document reveals how the peasants described their houses and their daily lives. Throughout his fascinating monograph, the author focuses on domestic life, especially those ideas related to the organization of space and time. He identifies interrelated sets of ideas and values concerning the practices of religion and magic, work and leisure, mortality and wealth, and the design and use of domestic space. This example of text analysis has not been widely adopted by architectural or housing historians, as subsequent paragraphs show, but it will be used as an important component of the research method to be elaborated and illustrated.

In contrast to this contribution, it has been common practice for economic and social historians to examine domestic buildings and residential quarters largely in terms of their layout and construction, or the development of building and domestic technologies. Other recent studies of housing and urban history have described either the layout of residential quarters, or the housing policies and financing implicated in their construction. In general, the interrelations between human ideas and values, and the design and use of dwelling units have commonly been overlooked. This recurrent shortcoming has led Swenarton to claim that social historians have ably dealt with economics, politics and society while ignoring design: ${ }^{4}$ the scant number of architectural plans in a journal of this kind tends to support his point of view. Moreover, Swenarton also stated that, in contrast to economic and social historians, architects and architectural historians have overlooked everything but the design of buildings. Both these approaches imply 'that design and society are not involved in a single process but are separate

3 E. Le Roy Ladurie, Montaillou: Cathars and Catholics in a French Village, 1294-1324 (Harmondsworth, 1980).

4 M. Swenarton, Homes Fit for Heroes: The Politics of Architecture of Early State Housing (London, 1981). 
and distinct'. ${ }^{5}$ This shortcoming cannot be levelled at a small yet growing number of studies in this field, as later sections discuss. None the less, Swenarton's interesting study of the design of housing units as a central issue of national politics and government policy in the United Kingdom overlooks the organization of the interior spaces of dwellings and the reasons for these layouts. Admittedly his study does consider some issues that are related to site planning, but his analysis of the layout of residential quarters is limited to the aesthetic composition of street-scapes. In sum, even though Swenarton's diagnosis of much contemporary housing research is correct, although exaggerated, we cannot comply with his analysis of the ideological nature of house planning. Consequently, his diagnosis and objection to it warrant further consideration.

The context in which residential buildings are constructed, even those with significant government subsidies, cannot be delimited to a political debate, as Swenarton implies. There are not only economic and political dimensions to workers' housing as this interpretation implies, but also an architectural one which includes the ordering of people, spaces and activities. Swenarton's interpretation is probably due to a misconception of the definitions of design and politics, which can be summarized as follows. The term design can be used to denote the ordering of the built environment, and the scheme of action to achieve desired ends. The term politics denotes government or government action; or it can also mean propaganda; or it can refer to the intentions and activities of eminent persons or groups of people. These definitions indicate that Swenarton adequately examines the diverse meanings of politics whereas he underplays the first interpretation of the meaning of design. Furthermore, these definitions also suggest that in order to overcome this kind of limitation it is instructive to examine the interrelations between design and politics in the context of housing by studying the ideas and values of diverse groups of people involved in the design and use of domestic space. Such an approach would also help to overcome some of the shortcomings of housing history briefly presented above. In order to achieve this goal, it is pertinent to adopt a dual-oriented approach founded on the systematic analysis of the organization and construction of domestic space by fieldwork and archival research as well as studies of descriptive and prescriptive texts concerning these buildings. The next section will discuss some theoretical and methodological issues related to this kind of approach.

\section{Theories and methods}

The organization of domestic and urban spaces, as well as their meanings 
and uses during the course of history, have been studied elsewhere: owing to the fundamental enduring quality of buildings, housing units of all kinds are handed down as a legacy from one generation to the next. They are one vehicle for the expression of social ideas and values which are reflected in the design and use of dwellings. This principle suggests that all buildings not only have a history related to their material conditions, but also a life-history that encompasses the human experience of them.

Given this principle, it is apparent that information embodied in the design of domestic space cannot be understood solely by a synchronic investigation, such as observation and documentation by fieldwork and/or analysis of floor plans. Such an investigation ought to be complemented by research methods that enable us to decipher how buildings were constructed and were used in former times. Such research methods include a temporal perspective that enables us to examine human values and ideas in relation to the construction and use of buildings during the course of time.

Ethnographies by several anthropologists indicate that the design and use of the built environment is not a mirror image of society nor of its social history, but one vehicle for the expression of social classifications which change over the course of time. Human groups and individuals are active agents that attribute values to their artefacts in accordance with sets of conventional meanings not inherent in the artefacts. Consequently, the term housing evokes a range of images and values: ${ }^{6}$ the meaning of housing, like the meaning of home varies from person to person, between social groups, across cultures, and during the course of time. Housing units are commonly attributed an economic value, an exchange value, an aesthetic value and a use value, whereas in addition to these, a home is usually attributed a sentimental and symbolic value. Whereas real estate agents are primarily concerned with the economic and exchange values of residential buildings, homeowners will not only share this concern but also complement it with an interest in aesthetic, use, sentimental and symbolic values that cannot be quantified and compared in monetary terms. All these values are not simply expressed by individuals but they are acquired, matured, transmitted, reinforced, or modified by interpersonal communication. Hence, communication between different groups of people classifies one or more systems of values in a society at precise points in time. In this respect, the design, the meaning and the use of housing units are very different when viewed by the inhabitants from 'the bottom up' and by architects, politicians and housing reformers from 'the top down'. From this perspective, it is instructive to distinguish between the tacit know-how used by local populations

6 For a more in-depth discussion of these issues refer to R.J. Lawrence, Housing, Dwellings and Homes: Design Theory, Research and Practice (Chichester, 1987), especially chapters 1, 2 and 3 . 
to construct their so-called vernacular houses, and the explicit know-how applied by decision-makers who usually do not live in the residential buildings they prescribe for others.

Alexander examines a fundamental difference between residential buildings in contemporary, industrialized countries, and vernacular houses in non-industrialized societies. ${ }^{7}$ He discusses how vernacular houses result from the unselfconscious ordering of design parameters by owner-builderoccupiers; in contrast, dwelling units in industrialized societies are the product of explicit design intentions formulated by administrators, landlords, and corporate clients that are translated into built form by architects and building contractors. Alexander notes that building construction methods in non-industrialized and preliterate societies are governed by complex, rigidly maintained unspoken rules and conventions that are shared and understood by indigenous populations. From this perspective, implicit norms produce dwelling units (and other buildings) with minimal variations at a specific point in time. Both the implicit parameters and the buildings evolve incrementally through the passage of time. In sum, when societies change from this mode of production to adopt specialized roles of professional groups for housing construction, buildings are no longer constructed according to tacit rules and conventions. Following that change, which has occurred at various times in different societies, incremental and adaptive transformations in dwelling designs are replaced by rapid and decisive developments that can be attributed to two factors. First, there are a decreasing number of material constraints for building in contemporary, post-industrial societies, owing to the proliferation of technologies which potentially increase the number and range of possible solutions, as Banham has shown. ${ }^{8}$ Second, there is the development of a range of construction specialists who have increasingly usurped the roles of the craftsman, master mason and inhabitant in the building construction process. Both these trends increased rapidly during the nineteenth century (but not in a chronological sequence) and they can be related to the increasing complexity of building construction techniques and the foundation of a range of 'urban specialists', including architects, public health officials and social reformers. Consequently, the relationship between 'the producers' and 'the users' of buildings, in general, and of housing, in particular, has become more complex. In general, the 'professionalization' of housing policies and practices gathered momentum during the nineteenth century. From then, it became rarer for architects to design dwelling units for specific individuals and more frequent for the client to be a government or private corporation, a company or financial institution, or a benevolent society. The

7 C. Alexander, Notes on the Synthesis of Form (Cambridge, Mass., 1964).

8 R. Banham, The Architecture of the Well-Tempered Environment (London, 1973). 
requirements of these institutions cannot automatically be equated with those of diverse individuals, and it has become increasingly common for the inhabitant of rental housing to be termed 'the anonymous client'. Furthermore, much of the negotiation related to design decision-making occurs prior to the architectural design process by housing administrators, legislators, property owners and reformers, who implicitly or explicitly make decisions that impinge upon the construction and layout of residential buildings. Consequently, the role of architects in the design of residential buildings appears to be confined to a task concerning aesthetic composition, whereas the inhabitant has no input in the design or the construction processes. In sum, by the beginning of this century, most housing construction processes in European cities bore no resemblance to the ways that vernacular dwellings were constructed previously. None the less, domestic space is much more than a commodity, or an aesthetic artefact, as discussed elsewhere.' In order to comprehend the complex range of meanings and uses that can be (and are) attributed to dwelling units, it is necessary to examine cultural, societal and individual human factors that are contextually defined in time and space. Hence, it is possible to compare the values and meanings that diverse groups of actors (including architects, housing reformers, landlords, tenants and politicians) attribute to domestic space at the same or different times. This kind of approach will now be elaborated and illustrated.

\section{Applications of theories and methods}

In order to address the principles outlined above, and to enrich our current understanding of those processes that led to the construction of tenements for the working classes during the second half of the nineteenth century, it is instructive to develop and apply a dual-oriented approach including studies of residential buildings and analysis of descriptive and prescriptive texts concerning the design and use of the buildings. This dual-oriented approach has been applied to examine the development of popular urban housing units in the French-speaking cantons of Switzerland according to the following procedure. Fieldwork studies were undertaken of the layout and design of a selected sample of 100 residential buildings constructed betwen 1860 and 1960 in Geneva, Fribourg and Le Locle. The fieldwork included some measured drawings of those residential buildings that were not already documented in archival records. Diverse documentary sources were also analysed, including plans of extant and non-built housing schemes (such as projects for competitions); descriptions and articles by architects on working-class housing; official publications including reports of government agencies, philanthropic societies, health and housing refor- 
mers, of building regulations and tenancy agreements; novels, autobiographies, brochures and newspaper articles reporting the attitudes, values and lifestyles of the residents. ${ }^{10}$

The preceding discussion suggests that there is a need for a systematic method for studies of one type of dwelling unit during the course of time, as well as a means for comparing different dwelling units at one point in time and over an extended period. Such an approach has only evolved and been applied in recent years.

It has become increasingly common for architectural researchers to undertake typological studies of the spatial order of buildings. This approach has been applied by Hillier and Hanson, and Steadman, amongst others. "The first step in this approach is to transcribe each house plan into an analytical diagram: each habitable space is represented by a circle, and the possibility of movement between these spaces is represented by a full line. This approach is applied to all interior spaces as well as spaces outside the dwelling uit. Hence, for any specific plan it is possible to represent the number of rooms, corridors and annexes as well as the interrelations between them and the exterior. Using this method, buildings that may appear to be very dissimilar can be seen to share an underlying structural pattern. This approach was ably illustrated by March and Steadman, ${ }^{12}$ with their analysis of three houses designed by Frank Lloyd Wright, shown in Figure 1. Although these houses look quite different they are in fact topologically equivalent.

The primary issue related to this kind of approach is to ascertain how the formal description of building layouts can be related to societal processes, including economic and political intentions and ideals, as well as interpersonal contact inside and around buildings. Any relationships between spatial organization and human activities ought to be substantiated by evidence stemming from sources other than the architectural plans of buildings. This discussion serves to illustrate that the systematic analysis of domestic space is not merely a means of visual representation but also a method of structuring information about the spatial organization of dwelling units. Consequently, it is considered to offer an important contribution for the study of housing history. Nevertheless, this method cannot yield any information about the meanings and uses of specific spaces: domestic space is not only created physically but is also ordered by cultural and societal parameters that are transient in kind and context dependent. These parameters influence the layout, the meanings and the uses of rooms and facilities. Therefore, to limit the historical analysis of housing to a study of

10 Lawrence, Le Seuil franchi ... .

11 P. Steadman, Architectural Morphology (London, 1983); W. Hillier and J. Hanson, The Social Logic of Space (Cambridge, 1984).

12 L. March and P. Steadman, The Geometry of Environment (London, 1971). 


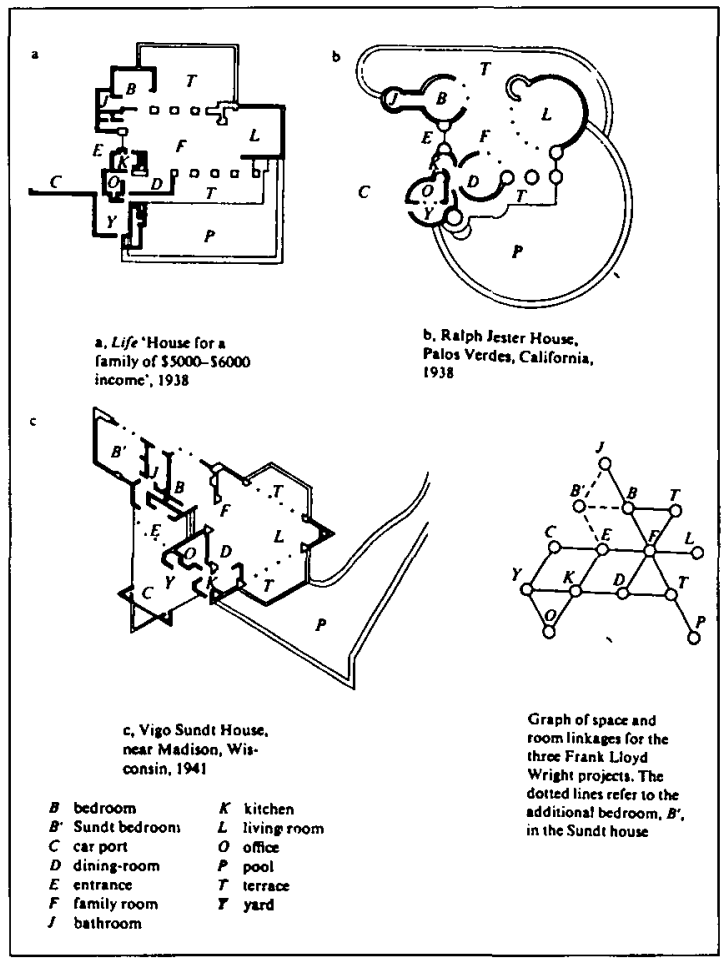

Figure 1: March and Steadman have shown how these three houses designed by Frank Lloyd Wright for different sites are structurally similar. (Reproduced by kind permission of $P$.

Steadman)

the configurations of dwelling units would be quite misleading, because the design, meaning and use of housing is not solely dependent on material factors. It is suggested that this approach can be complemented by a contextual study of the interrelations between the physical, societal and personal ideas and values that people attribute to domestic space and daily life. This kind of study stems from a discourse analysis of descriptive and prescriptive texts concerning the design and use of dwelling units.

Anthropologists and linguists have studied languages in order to identify the presence of classification systems and their relationship to the society in which they are created and used. The context and structure of classification systems are socially produced by the beliefs, ideas, intentions and practices of human groups. The existence of these cognitive structures and categories is a defining feature of both human languages and societies. Social classifications are one means of construing the world, of attributing meaning to things, and of deducing the meaning of things. Given that these classifications have such significant functions in human societies, there is 
no inherent reason why they cannot be used to interpret the meaning of the built environment, as some social anthropologists have shown. ${ }^{13}$

Social classifications are dynamic. They are an important means of acquiring, transmitting and transforming social processes and products. They have the dual potential of being (i) creative tools and (ii) instruments of regulation and control, as shown by biological taxonomies and theories of evolution during the last two centuries. The same is also true for the new classes of buildings - hospitals, offices, prisons and schools - that were commissioned and designed during the same period of time. Moreover, it was from the late nineteenth century that specific kinds of housing were commissioned and designed for precise groups of people. In Geneva, for example, the terms logement ouvrier (workers' housing), petit logement (small dwelling), logement économique (economical housing), logement à bon marché (cheap housing), and logement pour les personnes peu aisées (housing for persons with low incomes) were commonly used in public debate in the middle of the nineteenth century. Then, with the growing impetus of the housing reform movement, other terms were introduced such as logement hygiénique, logement salubre, and logement amélioré. These terms were complemented by others which specifically referred to the volume of residential buildings and the number of households they were intended to accommodate. For example, logement collectif referred to several tenements in one residential building; when the building was relatively large the term immeuble de rapport (a building yielding a return on investment) was used to underline the financial incentive of the owner, or the term caserne locative was used pejoratively to infer that large, ill-designed residential buildings were like military barracks. On the contrary, when there was only one residential building, the term logement individuel was used and it could refer to a detached, semi-detached or row house. This discussion illustrates that social classifications and written texts are commonly used, either implicitly or explicitly, to convey ideas, values and norms about human products and processes in general, and buildings in particular. Consequently, in order to complement the topological analysis of floor plans by accounting for those ideas and values related to the design and use of these dwelling units, it is instructive to examine the prescriptive and descriptive texts published by a wide range of people involved in the commission, design, construction and use of housing. This kind of approach is rare in architectural and housing history, largely owing to reasons outlined by Markus. ${ }^{14}$ The term

13 For example, S. Tambiah, 'Animals are good to think and good to prohibit', Ethnology, 8 (1969), 424-69; R. Needham (ed.), Right and Left: Essays in Dual Symbolic Classification (Chicago, 1973); E. Leach, Culture and Communication: The Logic by which Symbols are Connected (Cambridge, 1976).

14 T. Markus, 'From Tudor Walters to Parker Morris: prescription in housing design', in N. Teymur, T. Markus and T. Woolley (eds), Rehumanizing Housing (London, 1988). 
descriptive text refers to any published or unpublished document that describes the design and the use of artefacts, including housing units. Such documents include brochures, diaries and some professional publications such as pattern books. The term prescriptive text refers to any publication that prescribes how housing units (or parts of residential buildings) should be designed, constructed and/or used. This category of texts includes building codes, recommendations, legislation, and tenancy agreements which collectively prescribed how the ordering of domestic activities and spaces should occur inside residential buildings.

Analysis of these kinds of texts usually reveals collective, consensual ideas, as well as contrasts between different groups of people. However, one cannot overlook personal ideas and values of, for instance, architects, housing reformers and philanthropists concerned by the construction of housing in urban areas. Some of these became benchmarks for debate on housing issues from $1850 .{ }^{15}$ Indeed, our research of urban housing in the French-speaking cantons of Switzerland between 1860 and 1960, confirms that prescriptive texts have assumed an increasingly important role in relation to the layout, the design, and use of residential buildings since the professionalization of housing policies and practices gathered momentum during the last half of the nineteenth century.

Moreover, the descriptive texts examined in relation to urban housing in Switzerland - including newspaper articles, novels, minutes of meetings and published reports on housing conditions - describe extant dwelling units, their decoration and internal furnishings as well as some accounts of daily household life. Consequently, this category of text provides information that is pertinent to the historical research method advocated in this chapter.

In order to develop and apply a systematic analysis of -those ideas and values associated with the design, construction and use of dwelling units it is possible to apply an established set of techniques for discourse analysis, which have been published elsewhere and need not be repeated here. ${ }^{16}$ However, it is noteworthy that a study of the structure, the content and the nature of each text is usually identified and examined in terms of the contextual conditions in which that text was produced. This kind of approach can help us decipher the ideas, intentions, norms and values that form the framework of building codes, parliamentary reports and tenancy agreements. None the less, these kinds of texts can also be considered in

$15 \mathrm{H}$. Roberts, The Dwellings of the Labouring Classes (London, 1850).

16 For example, K. Krippendorf, Content Analysis: An Introduction to its Methodology (Beverly Hills, 1980); K. Rosengren (ed.), Advances in Context Analysis (Beverly Hills, 1981); A. Darmester, The Life of Words as the Symbol of Ideas (London, 1986); A. Greimas, R. Jakobson, M. Mayenova, S. Saumjan, W. Steinitz and S. Zolkiewski (eds), Sign-Language-Culture (The Hague, 1970). 
relation to building plans, construction specifications and photographic material, such that the task confronting a housing historian is a peculiar one. Apparently, no rigorous methodology is known to exist in order to proceed systematically.

Bearing in mind the current state of research, the study of urban housing in Switzerland that has been published ${ }^{17}$ endeavoured to identify:

1 ideas concerning the complex relationship between slum housing, mortality and social disorder, and how these were applied during urban renewal programmes;

2 ideas about how the term household should be defined, and about how that concept, notably the size and composition of households, influenced the design and use of dwelling units;

3 ideas concerning housing ownership, especially the nature of rental tenure, and the responsibilities of public and private institutions for the construction and management of dwelling units;

4 implicit and explicit agendas in housing regulations and tenancy agreements.

Though it is not possible to present all of these subjects here, the case study of Geneva which follows forms one part of that broader study of urban housing in the French-speaking cantons of Switzerland.

\section{Case study of urban housing in Geneva}

In 1814, there were 1,900,000 inhabitants in Switzerland and Geneva was the largest town with 21,800 residents. The growth of the population of Geneva during the nineteenth century is characterized by a rapid increase from 1850 owing to several sets of factors as both local and national levels, the primary one being immigration, as discussed later.

At a local level, 1851 marks the beginning of the gradual demolition of the medieval fortifications around the city. This process led to urban development beyond the boundaries of the ancient city. Land development and building construction became the concern of architects, engineers, building contractors, and they engendered a local political debate involving private companies, especially banks, benevolent societies and industry. ${ }^{18}$

At a national level, the mid-nineteenth century coincides with the beginning of a Federal government (founded in 1848) which led to new administrative buildings and new employment in cities such as Geneva. This period also corresponds to the growth of manufacturing industries, the development of financial institutions, the construction of the densest rail- 
way network in the world, and the construction of specific types of housing for a continually growing urban population.

Concurrently the subdivision of large apartments into relatively small dwelling units was common practice in many Swiss cities during the late nineteenth and early twentieth centuries. This practice is reported in the surveys of housing conditions at that time. ${ }^{19}$ Although the reasons for this practice have not been examined in detail by economic and social historians, they are worthy of consideration. They illustrate that the economic and use values of specific residential buildings can change significantly over relatively short periods of time. In this respect, it is noteworthy that it was customary in Geneva for both the middle and the working class to reside in the same residential building. In these so-called 'mixed buildings' the working class usually rented tenements of minimum size on the upper floors and in attics, whereas the middle classes rented apartments on the lower floors. This custom reflected the economic values of the dwelling units, as well as their social status and interior decoration. What is noteworthy, however, is that although this practice still remains in some contemporary cities including Geneva, the allocation of domestic space for specific classes of the population has been radically transformed: whereas in the nineteenth century the first floor of these residential buildings commonly contained the most prestigious and expensive apartments whilst the upper floors and attic were menial areas for servants' quarters, today, the upper levels of new buildings, including some renovated ancient attics, contain the most prestigious and expensive apartments whereas the first floor frequently contains small flats. This example serves to illustrate that the design, meaning and use of residential buildings are inextricably linked to societal values and customs that may change radically over relatively short periods of time.

In Geneva, it was not until land was developed beyond the ancient boundaries of the demolished fortifications that new buildings were specifically constructed to accommodate low-income households. These buildings commonly included ateliers or commercial facilities at ground level. It was not until after the First World War that tenement buildings became exclusively residential in function.

Following site visits to all existing residential buildings, analysis of the architectural plans indicates that it is possible to classify the housing units included in this study according to one or more of the following variables:

19 For example, H. Shorer, Les logements locatifs dans la Ville de Fribourg au Point de Vue économique et social, 1900 (Fribourg, 1908); F. Ferrière, Rapport sur les visites sanitaires instituées par le Conseil administratif de la Ville de Genève pendant l'été de 1884 (Geneva, 1885). 
1 aesthetic characteristics related to the composition of the building facades in terms of stylistic conventions (e.g. classical, neo-gothic, modern);

2 socio-economic variables related to the social status of the inhabitants (e.g. working class or middle class, blue or white collar workers);

3 the number, size and layout of dwelling units on each floor level of residential buildings (e.g. two or three rooms, a through floor plan, or only one facade with fenestration);

4 the age and construction of the buildings (e.g. timber-framed, brick or stone-walled);

5 the spatial organization of the floor plan in relation to the means of access from the public realm of the street to the private realm of each dwelling unit (e.g. passing through a private outdoor space, a shared external space and/or an internal space).

Using these variables, a descriptive typology of urban housing constructed for the working classes in Geneva between 1860 and 1960 has been elaborated. The typology includes:

Type 1: Tenement buildings, as shown in Figure 2, constructed in new urban quarters with an internal or external circulation corridor providing access to several dwelling units on each floor level; each tenement receives daylight from only one facade, either that oriented towards the street or the back court; each tenement has two or three rooms of similar size; there commonly is sequencing of rooms, and there usually is one shared toilet at each floor level.

Type 2: Tenement buildings, as illustrated in Figure 3, constructed in new urban quarters with an internal daylit lobby, staircase and landing providing access to two, three or more tenements on each floor level (two usually having a through type plan). Each tenement comprises two or three rooms of similar size and each is independently accessible from a central passageway or distribution space. These dwellings were usually not self-contained before 1900; thereafter they were, and they commonly included an additional room plus a bathroom.

Type 3: Dwelling units, as shown in Figure 4, built on suburban sites rather than in urban quarters, comprising two or three floor levels with a through type floor plan, built in terraces and accessible from the street through a private outdoor space. These dwellings were self-contained.

Type 4: $\quad$ Flatted dwellings with a through type floor plan, each tenement comprising three or more rooms, as shown in Figure 5, 
accessible from an external gallery at each floor level usually with a shared laundry accessible from each gallery. Prior to 1900 this type of tenement was not self-contained.

Type 5: Cottage dwellings, like those illustrated in Figure 6, with a through type floor plan either detached or semi-detached commonly with one or two floor levels (sometimes three) and completely self-contained.

Although this typology of popular housing is representative of those urban dwelling units constructed in Geneva, several qualifications must be made. First, examples of all these types were built concurrently at the end of the nineteenth century and did not follow a chronological sequence; for example, the first type was sparsely built in Geneva after 1890 (and was no longer built after 1914). Second, the relative numbers of each housing type built in Geneva varied considerably; for example, the second type is predominant throughout the whole period of this study. Third, with respect to all but the fifth housing type, it became increasingly common from 1900 to

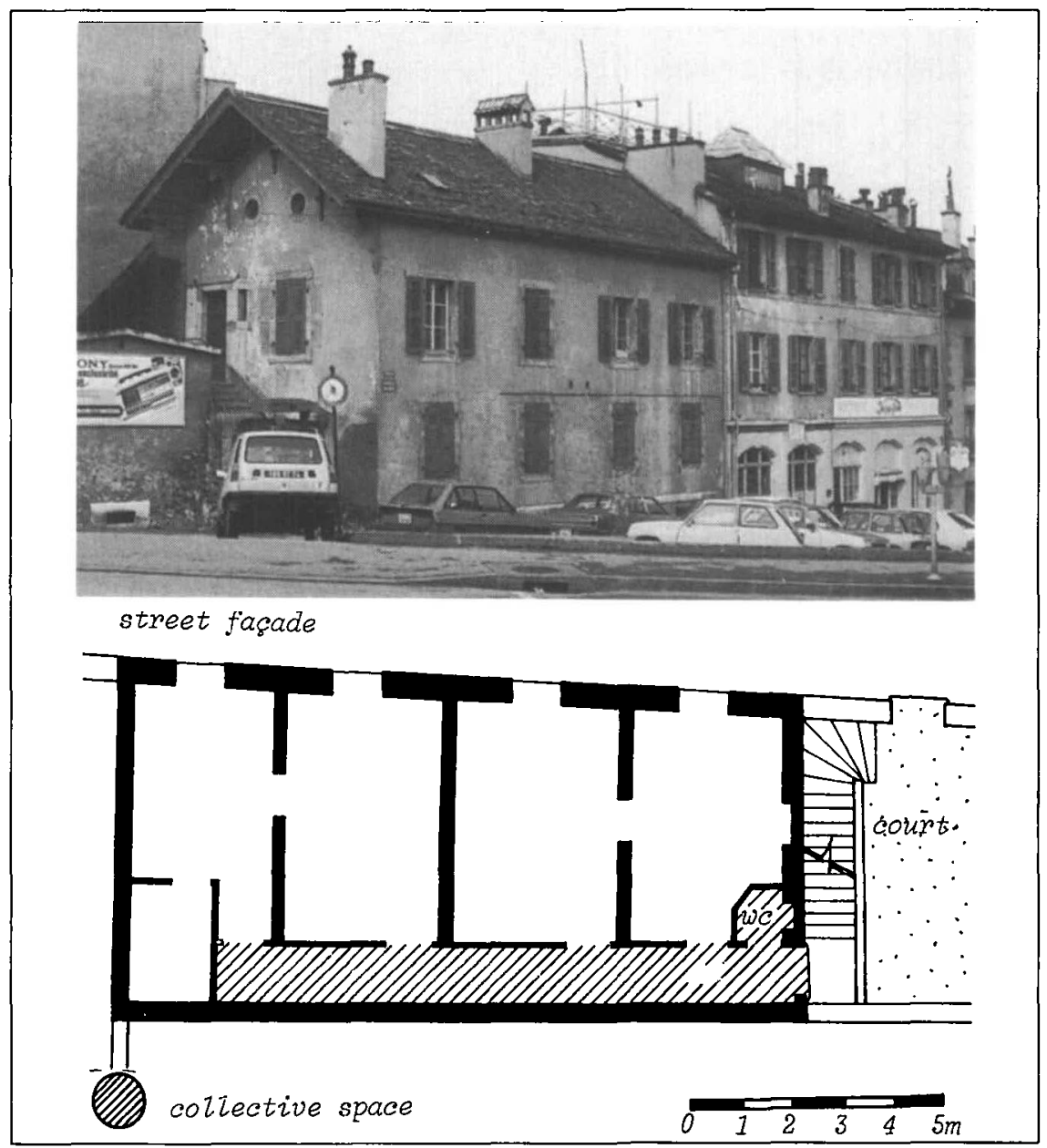

Figure 2: Example of house type 1, constructed at the ruelle du Midi, No. 14, in Geneva, in about 1860. 

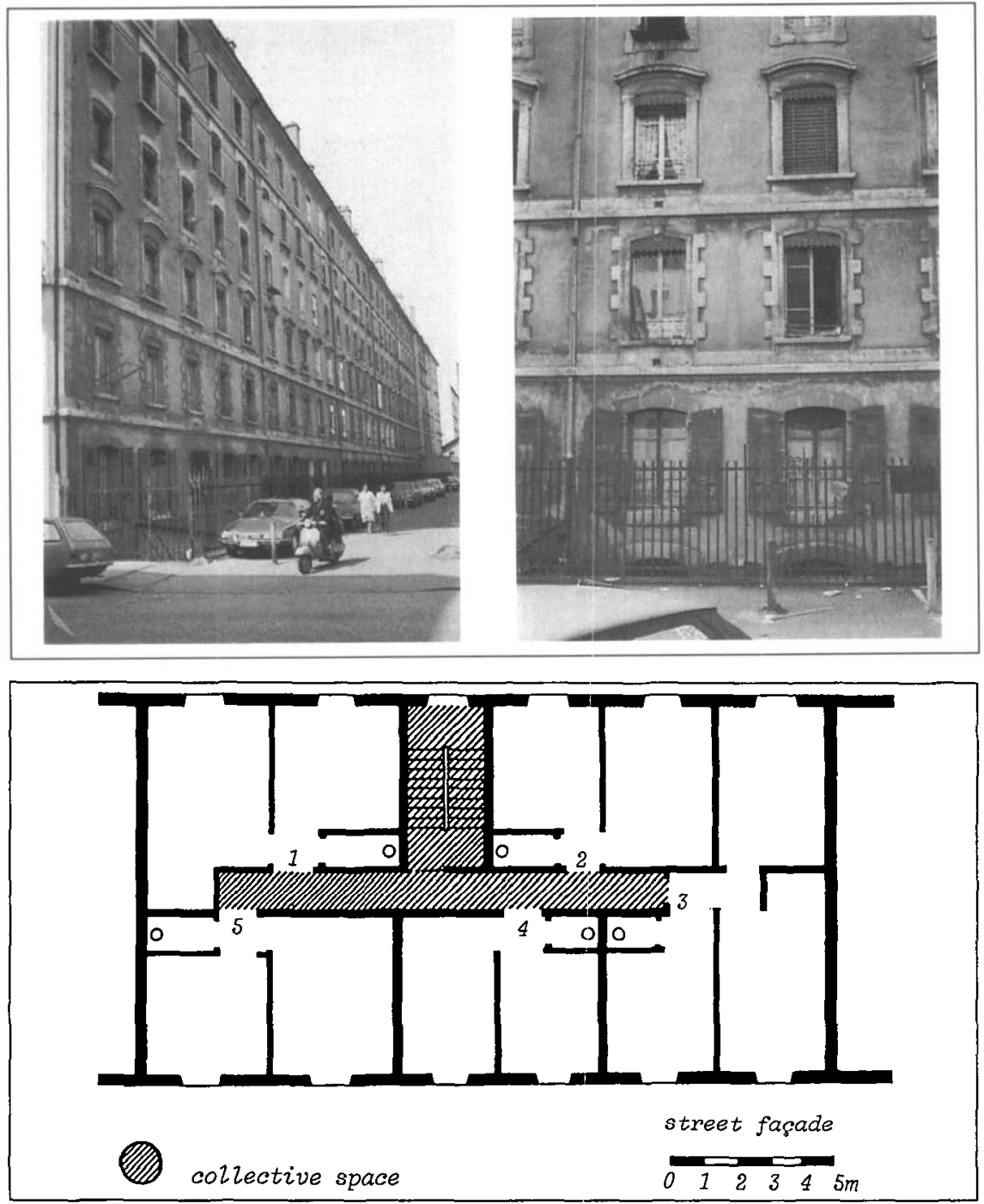

Figure 3: Example of house type 2, built at the Boulevard Carl-Vogt, in Geneva, in 1897 by the building contractor Jean Birmelé.

provide each dwelling unit with its own sanitary and cooking facilities, whereas during the nineteenth century these were commonly shared, being accessible from the interior, collective space.

During the period of this study, the small increase in the size of urban dwelling units can be contrasted with a significant improvement in the 


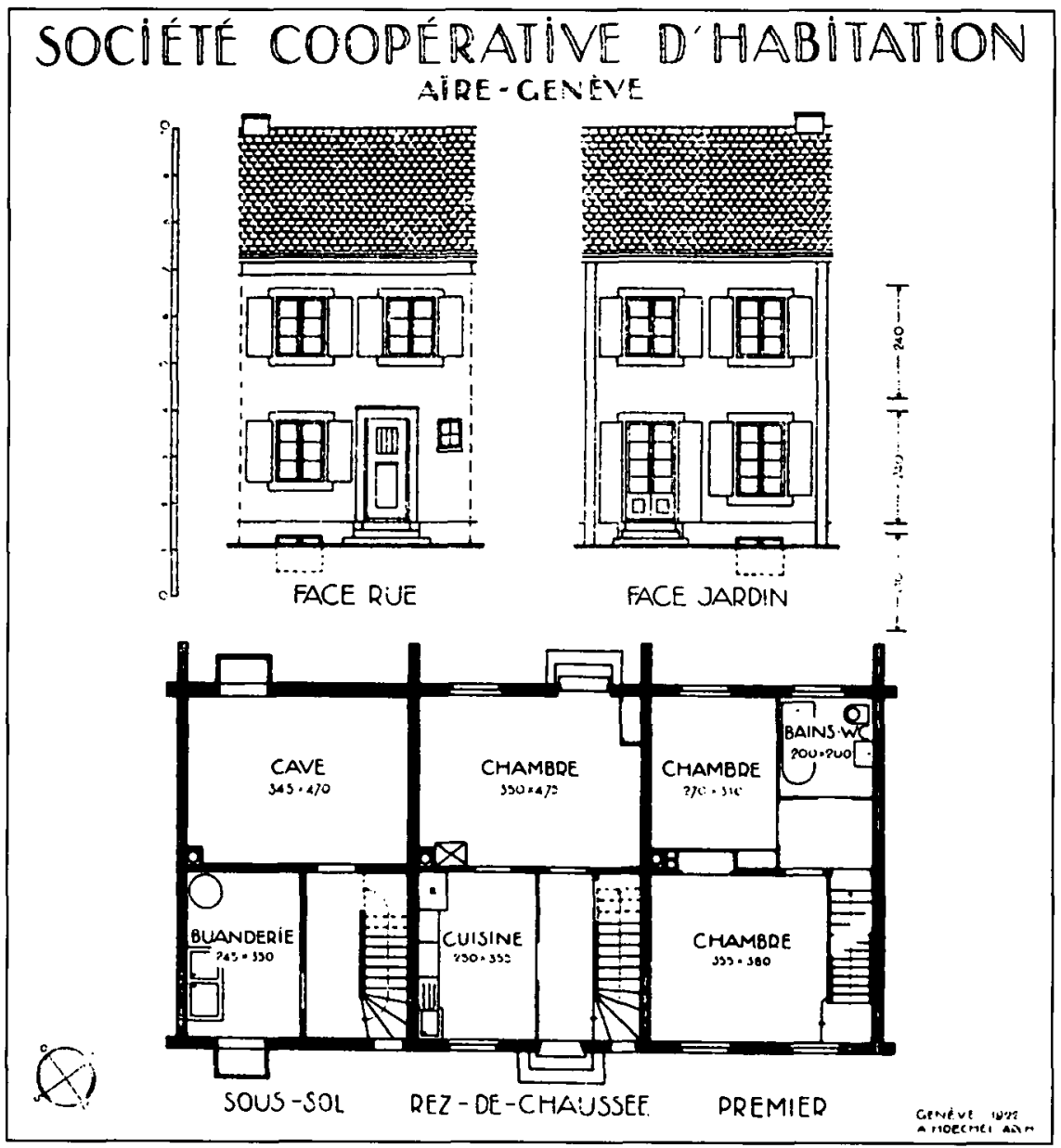

Figure 4: Example of house type 3, constructed at the garden suburb of Aire in Geneva during the 1920s, according to the plans of Arnold Hoeschel.

provision of private domestic services, and a marked decline in the number of persons per household. Hence, demographic, socio-economic and technological factors have been as influential as architectural factors in the decline of residential densities and changes to the use of public, collective and private spaces and facilities.

Developments in the layout and use of urban dwellings can also be considered in terms of private or shared domestic services for ablutions, laundry and cooking activities, and the notion of promiscuity. During the last half of the nineteenth century, the debate about the minimum standard 


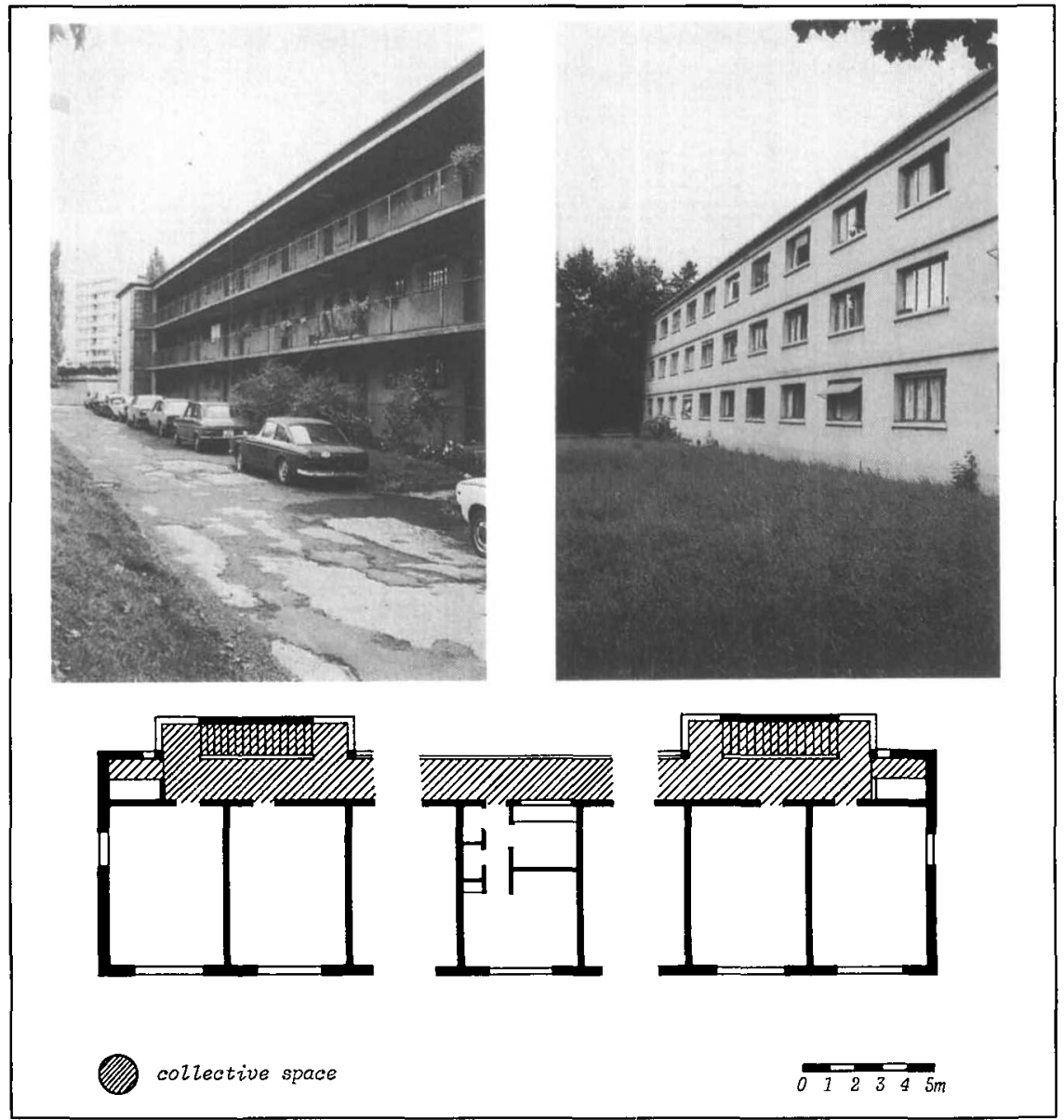

Figure 5: Example of house type 4, constructed between 1930 and 1932 at the Cité Vieusseux, in Geneva, according to the plans of Frédéric Mezger.

of an urban dwelling for 'the working classes' in Switzerland (and many other European countries), focused on the definition and design of selfcontained tenements, with private facilities and a separate bedroom for parents and children of different gender over ten years of age. The implications for house planning were explicit: the design and layout of rooms for specific household activities, and the controlled liaison between rooms, were the architectural elements intended to generate social reform by removing promiscuity. This architectural and moralistic concept linked the design of dwellings to moral well-being. The quest for improved housing conditions in urban areas led to the inclusion of new commodities begin- 

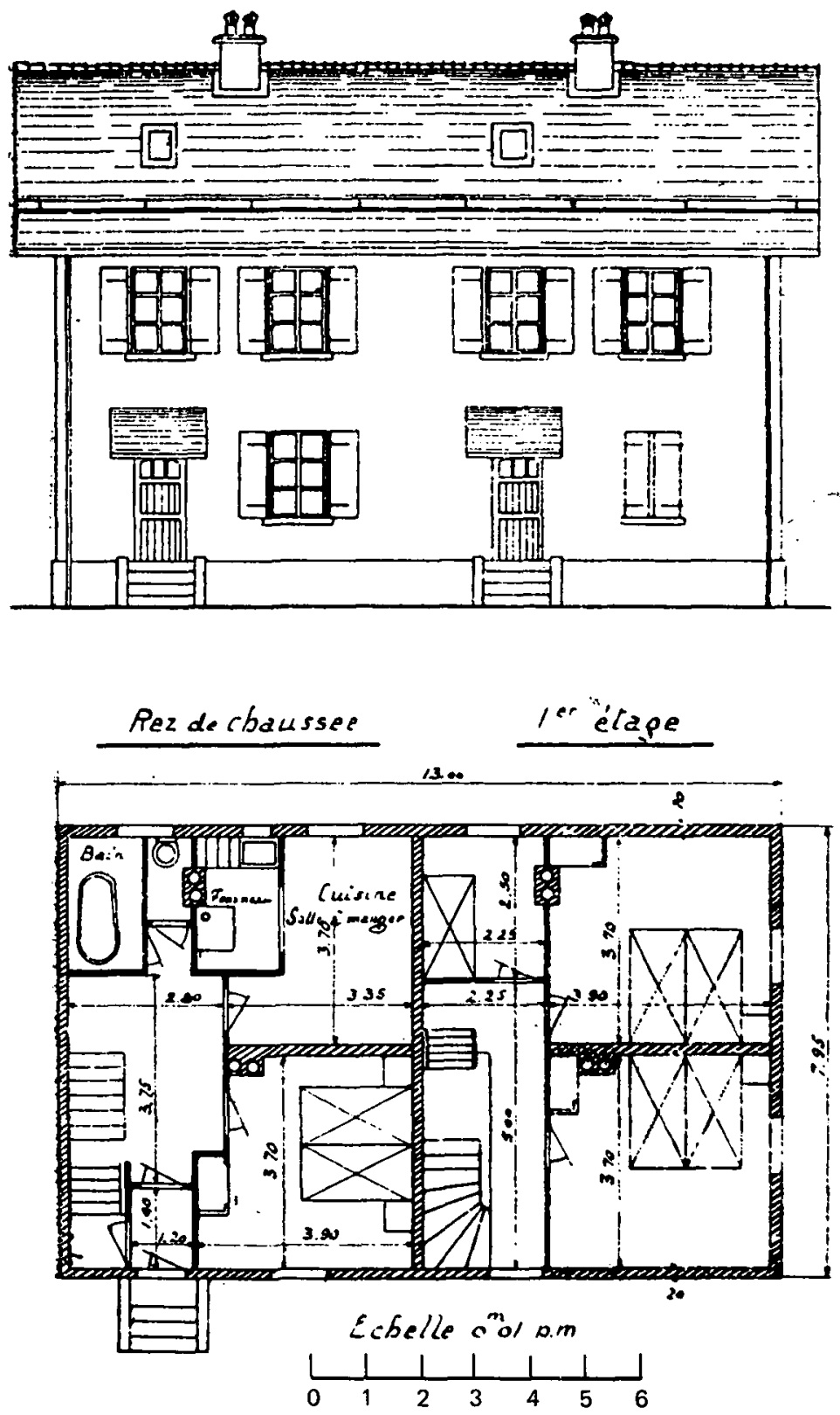

Figure 6: Example of house type 5, built in 1920 by the Association coopérative immobèlière de Genève, at Charmilles.

ning with a private toilet and kitchen, then a bathroom, in each dwelling unit. Although household laundry activities still occurred in a collective or public space, they were relegated to the basement. Consequently, demarca- 
tions between public, collective and private activities became more explicit than they had been beforehand.

Apart from changes in the design and use of private, interior spaces and facilities in urban residential buildings, there were also significant transformations in the design and use of external and internal shared spaces and facilities during the same period of time. Analysis of floor plans and fieldwork show that collective interior spaces (such as the lobby at ground level, and the staircase and its landings at the upper levels) were significantly changed from the late nineteenth century, by a reduction in size and decoration, the suppression of natural daylight from windows and/or skylights, the elimination of subtle changes in floor level, and the privatization of shared facilities, especially for ablutions. These trends have not only been observed in Geneva, but also the other Swiss cities examined in the study reported here. Collectively, they transformed the collective spaces that linked the front doorstep of each dwelling unit to the public realm of the street into a passage of minimal dimensions that could serve no other purpose than pedestrian circulation. Consequently, residents could no longer personalize the space adjacent to the front door step; children could no longer play in these shared spaces during inclement weather; and it became increasingly unlikely for neighbours to meet informally. It is instructive to examine why this occurred.

According to our research, the catalysts for the transformation of internal shared spaces and facilities were numerous, so that they can only be summarized here. First, they included techrical developments, especially the introduction of the lift as the principal means of vertical circulation. Over an extended period of time, the stair became a fire-escape. Second, innovations in domestic technology as well as the distribution of public services (e.g. gas, electricity and water), meant that private facilities for bathing, cooking and laundering were promoted. Last, but not least, a fundamental idea shared by many housing reformers of the late nineteenth century in Geneva was that different spatial relationships in urban dwellings engender different degrees of human interaction. This idea became the foundation of a principle of domestic culture that architects, landlords, stewards and reformers upheld and applied for the construction and management of urban dwelling units by:

1 reducing the size of communal space and by eliminating shared facilities, notably sanitary services, in order to minimize interpersonal contact between residents and reduce maintenance costs;

2 providing private facilities in each dwelling unit, which could be charged to the tenant by increasing the rent; the tenancy agreement also stipulated that the tenant was responsible for the maintenance and repair of these facilities; 
3 prescribing how both interior and external spaces and facilities ought to be used by tenants; these prescriptions formed part of the responsibilities of tenants that were explicitly stated in tenancy agreements; caretakers were employed to control the behaviour of the residents.

Beyond the realm of interior collective spaces and facilities, immediately outside and around residential buildings, there were also significant changes during the period of study. Fieldwork and plan analysis show that from the last decade of the nineteenth century it became increasingly common for residential buildings to be set back from rather than aligned along streets, alleys and courts as had been the custom in Geneva, and other Swiss towns, until that time. This gradual change (which increased after the First World War) meant that the collective, interior space was no longer directly linked to the public realm of the street: an external, uncovered space simultaneously linked and separated these two domains. It has been observed in Geneva, and other Swiss towns, that this external space was often a small garden between each building and the footpath. However, since the 1920 s it has increasingly become a vast, landscaped area, sometimes with car-parking, that frequently encircles all four sides of residential buildings. Research has indicated that no building or town-planning regulations prescribed these changes, nor did government or local populations intervene in an attempt to suppress them. None the less, urban renewal was decried by local journalists; but architects, landlords and social reformers were unheeded in their quest for a sane and orderly urban environment.

Collectively, the preceding changes to the design and intended use of the internal and external private and shared spaces and facilities have been significant. They contribute to the realignment and the redefinition of physical, administrative, judicial and symbolic barriers and borders that demarcate and associate private, collective and public domains in urban residential quarters. It now remains for us to examine those ideas and values mentioned above that were applied during the period of our study in order to design new urban dwelling units.

The sordid conditions of urban quarters in Geneva, and other Swiss towns, became a preoccupation of public health reformers and architects during the last half of the nineteenth century. For example, in 1866, Gustave Moynier $^{20}$ claimed that it was necessary to encourage internal, private activities for all age groups of urban populations in order to overcome contact with the vices of the street and tavern. Moynier championed the goals of literary and music societies, gymnastic clubs, and Sunday schools, because they enabled citizens to use their spare time in 'agreeable ways'. Moynier, like some architects in Geneva at that period, condemned public 
thoroughfares, not simply because they were narrow, unclean and inadequately drained, but also because they encouraged the 'propagation of vices'. From this perspective, sanitary reforms were closely allied to moralistic ideals. This ideology was not limited to prescriptions about the design and use of domestic space, but also encompassed the planning of urban neighbourhoods.

The first comprehensive survey of the housing conditions of the urban quarters was completed by $\mathrm{Dr}$ Ferrière in 1884, at the request of the Municipality of Geneva. ${ }^{21}$ The inner city was subdivided into districts or zones. Within each district a street by street survey of each residential building was completed. The surveyors noted the number, size and condition of each dwelling unit, and the number, size and condition of water closets, kitchens, water supply and drainage. The findings of this survey showed that insalubrious housing was much more prevalent than anyone had predicted, and that the causes of insanitary conditions were, first and foremost, the lack of building maintenance; second, defective construction, especially related to drainage and waste disposal; and third, the relatively high number of residents per habitable room.

In 1891, when Charles Barde published his monograph Salubrité des Habitations et Hygiène des Villes, ${ }^{22}$ he maintained that the overcrowding noted by Dr Ferrière was primarily due to speculative building construction and that this practice was the main factor that contributed to insanitary housing in Geneva at the end of the nineteenth century.

In sum, authors like Barde, Ferrière and Moynier were representative of many of their contemporaries - especially in the architectural and medical professions - who shared the belief that insanitary housing did not only induce ill-health but also nurtured immorality. The same kind of reasoning was presented by authors of housing surveys in the Swiss cities including Basle (1889); Lausanne (1894); Bern, Winterhur and Zurich (1896); Lucern and St Gallen (1897); and Fribourg (1897-1903). In general, there was little concern about the economic and political dimensions of insanitary housing. However, Dr Ferrière maintained that sanitary regulations should be drafted and enforced by the Municipality of Geneva. The rationale of his point of view was largely overlooked by local politicians, who generally maintained that the provision of good housing was a proper task for private enterprise not hindered by government.

The lack of intervention by federal, cantonal and municipal governments in the housing market is due to the principle that housing construction and management is the province of the private sector. The private housing and building sector has been fed by foreign capital, especially from France, and

22 C. Barde, Salubrité des Habitations et Hygiène des Villes (Geneva, 1891). 
this custom was so prevalent in Geneva by the end of the nineteenth century that numerous limited property companies flourished at that time. Babel states that 1,800 companies were estimated in Geneva in $1919 .{ }^{23}$ The investors in limited property companies, like investors in a Swiss bank, are guaranteed their anonymity. This guarantee ensures protection from investigation by foreign political and financial authorities. It also implies that our study of housing ownership and tenure cannot provide explicit information about the number and kinds of investors in the housing stock. Moreover, this statute means that tenants cannot deal directly with the building owners but must address themselves to a third party, often a steward.

A Société des régisseurs (Society of Stewards) was founded in Geneva in $1879 .{ }^{24}$ This society, the first of its kind in Switzerland, provided a platform for estate agents, solicitors and notaries who adminstered buildings owned by individuals and limited property companies. It was responsible for the formulation and application of codes of conduct that were primarily intended to regulate the use of domestic space by tenants. These codes of conduct became part of the tenancy agreement. Given that certain activities - children's play, drying clothes and household chores - often occurred in collective spaces, apparently against the wishes of landlords and stewards, these codes reveal the power and strategy of stewards to reorder domestic activities by replacing those domestic chores that usually took place beyond the threshold of each dwelling inside the unit itself. Moreover, caretakers were employed by stewards, on behalf of property owners, to ensure that tenants complied.

In 1893, the Société des régisseurs de Genève published a document titled Recueil des règles et usages locatifs à Genève, the first comprehensive document, to our knowledge, published in Geneva that stipulated the responsibilities of the landlord and tenant of rental dwelling units. Although it has not been possible to establish why this document was formulated in 1893, it is not unreasonable to suggest that it was necessary to fill a void that neither federal nor local governments intended to occupy. The content, nature and structure of these contractual requirements have been examined in order to illustrate the kinds of information that discourse analysis can provide in order to enrich our understanding of those prescriptive ideas and societal values associated with the use of space inside dwellings units.

This document includes four sections. The first section, titled 'Observations préliminaires' includes only one article that informs the tenant of his responsibility as 'the guardian' of the premises. According to Swiss federal

23 A. Babel, La Caisse hypothécaire et le développement économique du Canton de Genève (Geneva, 1947), 443-4.

24 J. Candaux, La Société des Régisseurs dans la vie genevoise (Geneva, 1979). 
law, the tenant should inform the lessor (the landlord's steward) of any repairs that are required.

The second section, titled 'Entrée du locataire', includes two articles. The first states that the premises shall be rented after they have been swept clean. Moreover, the cost of any further required cleaning, or the waxing and polishing of floors, shall be charged to the incoming tenant. The second article states that the lessor is not responsible for sweeping chimneys when there is a change of tenant.

The third section, titled 'Règles générales relatives à l'usage des locaux loués' includes twenty-five clauses that prescribe the responsibilities of the lessor and the tenant with respect to the occupation and use of dwelling units.

This document was signed on 10 May 1893 by fifteen stewards who managed properties in Geneva. Analysis of this document, as well as the serial of texts that have been published since, shows that the interaction between landlords and tenants was not usually a personal one as Englander found in Britain at the same period of time; ${ }^{25}$ rather it was an unbalanced relationship prescribed by legal clauses. An understanding of the structure, content and nature of these prescriptive clauses indicates the subordinate position of tenants. Landlords could dictate how tenants should (and should not) use space inside dwelling units, while maintaining them in order. It is noteworthy that the responsibilities of the lessor are defined in only three of the above-mentioned articles. Given that at least two-thirds of the housing stock in Geneva was (and still is) in the private rental sector, and that tenancy agreements were not regulated by parliamentary laws, the working classes had no alternative but to rent from landlords or stewards, and they were compelled to comply with these stipulations for fear of eviction.

The above-mentioned document became the first of a long serial of regulations that prescribed the duties of landlords and tenants. All of these texts cannot be analysed or presented here.

Although the preceding regulations became an integral part of tenancy agreements, landlords and stewards also found it necessary to formulate 'règlements du maison' (rules of the house) which they commonly had posted on a board in the lobby near the entrance of residential buildings. André Schnetzler, a lawyer in Lausanne who was concerned with housing reforms, formulated and published the first document of this kind in 1892. This document contained eleven clauses that specifically stipulated how the tenants ought to use the collective space and facilities inside the building. They prescribed when the entrance door should be locked each night, that the tenant should maintain the collective space in a clean condition, 
that no personal belongings should be left in the lobby or on stair landings, and that no cleaning chores should be done in the internal collective space.

Analysis of diverse documentary sources, particularly the housing surveys mentioned earlier, indicate that the 'règlements de maison' were intended to control how residents used collective spaces and facilities, apparently because the daily activities of many tenants did not correspond with the intentions, or the ideals, of landlords and stewards. In sum, it was not merely architectural design but also prescriptive codes of behaviour that jointly were used in an explicit manner to reorder the use of space and facilities in urban residential buildings during the period of this study. Such mechanisms are still applied, often following modifications, in Geneva and other Swiss cities today.

\section{Synthesis and conclusion}

The preceding sections have examined the spatial organization of, and those ideas and intentions attributed to, the predominant types of rental dwelling units constructed in Geneva from 1850.

The spatial, societal and temporal perspectives presented enable us to identify the similarities and differences in the design, meaning and use of dwelling units in the same city or town at one point in time, and over an extended period, as well as in different cities. In this respect, when the analysis presented herein is reapplied to examine workers' housing in other cities and towns, it becomes clear that it was the internal layout and the use of tenement buildings that differed significantly from the design of dwellings for artisans and other classes. Perhaps the most apparent differences concerned the organizations of shared spaces and facilities, especially for access from the street to the entrance of each dwelling unit, and the location of facilities, including water services (for example, the laundry and water closet) initially only accessible from the collective space.

With respect to shared circulation spaces within residential buildings, it is noteworthy that although all the different classes of buildings included one staircase providing access to all dwelling units, in the workers' tenements there were usually four or more flats accessible from the stair and the circulation space at each floor level. In the middle-class apartment building, however, it was common for two or three flats to be directly accessible from the stair landing at each floor level. When a kitchen was provided in a workers' tenement it was usually directly accessible from the circulation space, it provided access to other rooms in the tenement, and it did not always have natural light and ventilation. None the less, it did contain the hearth, the sole source of heating and this symbol of domesticity was an important asset.

This spatial layout of workers' tenements inevitably enhances interper- 
sonal contact between tenants who are not members of the same households, or of the same family. The daily use of shared circulation spaces, toilets, laundries and (sometimes) kitchens, meant that contact between neighbours was inevitable. It is suggested that the reorganization of these spaces and facilities was the overriding concern of the housing reform movement that remained camouflaged by the debate on sanitary reforms. In the case of Swiss cities like Geneva, the quest of architects, landlords and stewards to suppress collective living practices cannot be questioned.

In other terms, social classifications were employed to redefine the spatial relationship between tenement buildings and the public realm of the street; redefine the spatial relationships inside buildings; and reorder domestic activities by removing any that occurred in collective spaces, either to the private realm of the dwelling unit or to the external public space. This reordering process was formulated and applied by architects, property owners, housing and social reformers, and stewards, without regulation by government or contest from tenants. At this stage, much more research needs to be devoted to explaining the reasoning behind this reordering process, the apathy of government officials and tenant associations, and the consequences of both. For example, to what degree did these attitudes and behaviours reflect a social consensus about the diffusion of the domestic culture of the middle and upper classes down to the ranks of the workers? To what extent did the provision of commodity and convenience inside dwelling units serve as a carrot for workers' civism? Despite the benefits of providing private services and commodities inside workers' housing, what were the costs to the residents and to society at large? These questions are yet to be answered by housing historians.

In sum, the study presented here shows that the 'commodification of domestic space' gathered momentum from 1850 and that a wide range of factors were implicated in this process. The integrative approach presented and illustrated in this chapter provides some clues for further research on this concept, as well as a means of examining the unanswered questions and directions for future work on this complex subject. This contribution will, it is hoped, provide a catalyst for the diversification and integration of studies of housing history thereby enriching this fascinating yet difficult domain of enquiry.

University of Geneva 